\title{
Videogame playing as distraction technique in course of venipuncture
}

\author{
Giocare con i videogiochi come distrazione attiva in corso di venipuntura
}

M. Minute, ${ }^{1}$ L. Badina, ${ }^{1}$ G. Cont,${ }^{1}$ M. Montico, ${ }^{2}$ L. Ronfani, ${ }^{2}$ E. Barbi,${ }^{3}$ A. Ventura ${ }^{1}$

Key words: videogame; pain control, venipuncture; children

\section{Riassunto}

Le procedure di venipuntura ed incannulamento venoso sono la causa più comune di dolore e distress nel bambino. Ridurre il dolore e l'ansia ad esse correlati potrebbe essere importante per prevenire le reazioni di distress in corso di ulteriori procedure, soprattutto per quei bambini con patologia cronica che necessitano di controlli o ricoveri multipli.

L'obiettivo di questo trial randomizzato controllato, condotto in aperto, è stato quello di valutare nel bambino l'efficacia dell'aggiunta di una strategia di distrazione attiva (videogame) sul dolore procedurale da venipuntura.

Metodi: Sono stati reclutati 109 bambini di età compresa tra i $4 \mathrm{e} \mathrm{i}$ 10 anni; di questi 97 sono stati randomizzati e suddivisi in due gruppi: un gruppo di controllo (CC) che ha ricevuto solo le cure convenzionali, ovvero la premedicazione con EMLA, e un gruppo sperimentale $(\mathrm{AD})$ in cui alle cure convenzionali è stata aggiunta la distrazione attiva con videogame. Gli outcomes valutati sono stati il dolore riferito dal bambino, per mezzo della scala di autovalutazione FPS-R; la reazione comportamentale al dolore valutata da un osservatore secondo la scala FLACC; il numero di tentativi necessari per il successo delle procedure di venipuntura o incannulamento venoso. Risultati: In entrambi i gruppi la mediana dei punteggi FPS-R è stata 0 , con un dolore significativo (FPS-R>4) riportato dal $9 \%$ dei sog-

\footnotetext{
Department of Pediatrics,

2 Unit of Epidemiology and Biostatistics,

3 Department of Pediatric Emergency,

Institute for Maternal and Child Health IRCCS Burlo Garofolo,

University of Trieste, Italy
}

Indirizzo per la corrispondenza (Corresponding author):

Marta Minute, MD

Clinica Pediatrica IRCCS Burlo Garofolo, University of Trieste

Via dell'Istria 65/1 34137 Trieste (Italy)

Telephone: +393333518681/+39040569910

e-mail: martaminute@gmail.com getti. La mediana per quel che riguarda la scala FLACC è stata pari a 1 in entrambi i gruppi, mentre la percentuale di bambini con dolore grave (FLACC >4) è stata del 18\% nel gruppo di controllo e del 9\% in quello sperimentale; tale differenza non è statisticamente significativa $(\mathrm{p}=0.2)$. La mediana dei tentativi necessari è stata pari a 1 in entrambi i gruppi, con un range interquartile compreso tra 1 e 2. La distrazione attiva è stata applicata con facilità ed accettata molto bene sia dai bambini sia dagli operatori.

Conclusioni: La distrazione attiva non migliora l'analgesia già fornita con EMLA per quel che riguarda le procedure di venipuntura ed incannulamento venoso, ciò nonostante è risultata essere facilmente applicabile e apprezzata dai bambini. Potrebbe essere utile indagare questa tecnica di distrazione in corso di altre procedure dolorose.

\section{Abstract}

Background: Needle-related procedures (venipuncture, intravenous cannulation) are the most common source of pain and distress for children. Reducing needle related pain and anxiety could be important in order to prevent further distress, especially for children needing multiple hospital admissions.

The aim of the present open randomized controlled trial was to investigate the efficacy of adding an active distraction strategy (videogame) to EMLA premedication in needle-related pain in children.

Methods: One-hundred and nine children ( $4-10$ years of age) were prospectively recruited to enter in the study. Ninety-seven were randomized in two groups: CC group (conventional care: EMLA only) as control group and $\mathrm{AD}$ group (active distraction: EMLA plus videogame) as intervention group. Outcome measures were: selfreported pain by mean of FPS-R scale (main study outcome), observer-reported pain by FLACC scale, number of attempts for successful procedure.

Results: In both groups FPS-R median rate was 0 (interquartile range: $0-2$ ), with significant pain (FPS-R $>4$ ) reported by $9 \%$ of 


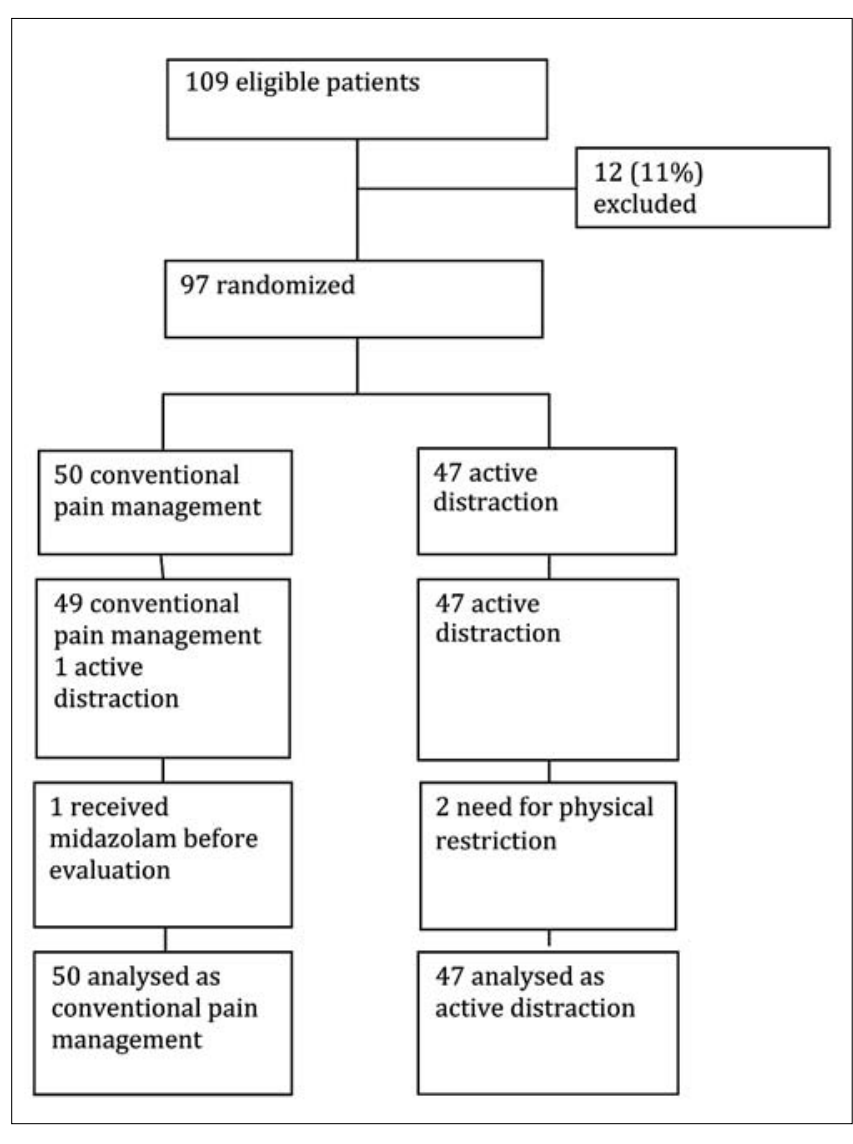

Study algorithm (intention-to-treat analysis)

Figure 1.

subjects. FLACC median rate was 1 in both groups (interquartile range 0-3 in $\mathrm{CC}$ group; 0-2 in $\mathrm{AD}$ group). The percentage of children with major pain (FLACC $>4$ ) was 18\% in CC group and 9\% in $\mathrm{AD}$ group $(\mathrm{p}=0.2)$. The median of necessary attempts to succeed in the procedures was 1 (interquartile range 1-2) in both groups..

Conclusion: Active distraction doesn't improve EMLA analgesia for iv cannulation and venipuncture. Even though, it resulted in an easily applicable strategy appreciated by children. This technique could be usefully investigated in other painful procedures.

\section{Introduction}

Needle-related procedures such as venipuncture or intravenous cannulation are commonly performed both on healthy (routine blood sampling) and ill (in- and outpatients) children ${ }^{1}$. They are, therefore, one of the most common source ${ }^{2}$ of pain and distress for children: the pain due to these procedures is rated from moderate to severe in $36 \%$ of children 3 to 6 years of age and in $13 \%$ of children 7 to 17 years of age; pain, including the mild one, was described in more than $50 \%$ of patients in both population ${ }^{3}$.

Unmanaged pain and distress may have clinical implications on children ${ }^{4}$, such as acute vasovagal responses, change in heart rate and stress hormone levels, chronic needle phobia and avoidance of health cares. Therefore the necessity of pain management is now consolidated: the approach can be both pharmacological and non pharmacological and often these approaches are integrated.

Non pharmacological approach is based on different techniques ${ }^{8}$ such as preparation programs $s^{6,7}$, correct positioning9 and both passive (movies, toys, music, bubble bowling etc ${ }^{10}$ ) and active distraction. Distraction is described as "a class of cognitive strategies that divert attention from a noxious stimulus through passively redirecting the subject's attention or by actively involving the subject in the performance of a distracter task" ${ }^{11}$. Distraction affects the perception of pain both indirectly (attention capabilities are finite and distraction can consume some of them, leaving less focus available to perceive pain ${ }^{12}$ ) and directly (distraction interferes with neuronal activity associated with pain ${ }^{13}$ which is modulated by a gating mechanism influenced by cognitive processes ${ }^{14}$ ).

While passive distraction's techniques 10,8 have been investigated in many studies, that show that this kind of pain management interferes with pain perception thus modifying the quality of pain itself $15,16,17$, active distraction's effectiveness is not well defined.

The aim of this study was to investigate the efficacy of an active distraction strategy (video-game playing) compared to our standard procedure (topical anesthetic cream) in children 4 to 10 years of age.

\section{Materials and methods}

\section{Study Design:}

The study was an open randomized controlled clinical trial. It was designed to test the effectiveness of active distraction with a videogame on procedural pain due to IV cannulation and venipuncture. The study took place in a Pediatric Third Level teaching hospital, at IRCCS "Burlo Garofolo", Trieste, in the Pediatric Clinic, Gastroenterology Service and Day Hospital of the Institute, where children were recruited.

The study was initiated and designed exclusively by the investigators and its protocol was approved by the Independent Bioethical Committee of the Institute. Parents of all children provided written informed consent.

The videogame console (Nintendo ${ }^{\circ}$ ) and the video-game CD WiiPlay ${ }^{\circ}$ were donated by an association of volunteers offering time to hospitalized children. The researchers had all the responsibility in the design of the study, the collection and the analysis of the data, the presentation of the manuscript and the decision to submit the manuscript to publication.

\section{Patients:}

From April to December 2009 we offered study entry to all children 4 to 10 years of age, who needed to undergo IV cannulation and venipuncture. Exclusion criteria were: positive history for epilepsy: known hypersensitivity to amide anesthetics; impossibility for the personnel to execute the procedure on the hand or on the elbow; impossibility for the child to cooperate and play with the videogame.

Once eligible children were identified, parents were both provided a pamphlet and orally instructed about the study and the proce- 
dures to let them decide whether they wanted their child to enter the study and to sign the informed consent. After that, children enrolled were randomly assigned to control or experimental group. Randomization procedure was managed by an independent statistician at the Epidemiology and Biostatistics Unit of the Institute using a computer program. Randomization list was generated in blocks of 10 . The allocation concealment was guaranteed through the use of closed opaque envelopes, numbered consecutively. In each envelope the assignment group was indicated, based on randomization. Medical personnel directly involved in the management of the patient opened the lowest numbered envelope available and assigned the patient to the correspondent group.

\section{Procedure:}

Pediatric nurses premedicated children by applying EMLA ${ }^{18,19}$ cream, on both the dorsum of the hands and the antecubital fossas; the cream was maintained on the skin at least 60 minutes, by mean of an occlusive dressing. After 60 minutes or more, the children and their parents were invited to the medication room, where nurses removed the dressing and the cream and explored the application sites to find the best vein to be cannulated. The procedure was explained step by step to children and parents.

All the procedures were routinely performed with the parent seated and the child seated on parent's legs, unless the child chose to sit by his own to be more comfortable. The child's arm was leaned on the operating bed.

For children in the control group the procedure was at this point performed with no further device.

Children assigned to experimental group, on the other hand, were shown at this point the distraction device: it consisted on a simple videogame, Wii-Play ${ }^{\circ}$, rated $3+$, in which the child had to aim to different targets using a single-handed remote as a pointer. In order not to false study's results, all children played the same game and we didn't allow them to familiarize earlier with the game since this would have not been adherent to hospital's routine reality. The console was at least 1 meter away from procedural site, in order not to interfere with nurse's work, and the remote, wrapped in a rubbery shell, was secured with a lace to the children's wrist on the side where the procedure wasn't being attempted. The children were instructed to aim a the target and to try to concentrate on the video in front of them. They were allowed both to play more than a match if the procedure required more than one attempt and to finish the match when the procedure was faster.

\section{Data Collection:}

While the children underwent the procedure, an observer filled in the form with personal (date of birth, sex) and procedural data (kind and site of procedure, number of attempts to perform a successful procedure).

Primary outcome of the study was self-report level of pain evaluated with Faces Pain Scale Revised (FPS-R) 20,21. When the procedure was over, the child evaluated the pain by choosing on the FPS$\mathrm{R}^{20,21}$ between six faces that represented different levels of pain, from no pain to the worst pain ever. The rate was then translated into numbers from 0 to 10 , with 2, 4, 6 and 8 as intermediate scores. (Fig 2)

Secondary outcomes were: 1) the children's reaction to pain evaluated when the procedure was over by the observer through the FLACC behavioral scale and 2) the number of attempts needed to perform a successful procedure. The FLACC tool assesses changes in five categories of behavior (namely: Face, Legs, Activity, Crying and Consolability), rating each one on a scale of $0-2$ (Table 1 ). Ten is the maximum score indicating severe pain and a score $<2$ generally indicates absence of pain 22,23 . A FLACC score higher than 4 is considered as indicator of moderate pain ${ }^{24}$.

\section{Statistical Analysis:}

Based on available literature ${ }^{25,26}$ we assumed a mean FPS_R score of 2.5 (standard deviation=1.8) in the EMLA control group. We estimated a priori that the enrollment of 100 children would provide the study with a statistical power of $80 \%$ to detect a 1 point reduction from this assumed mean pain score in children allocated to EMLA + distraction device, given a two-sided type 1 error of 0.05 .

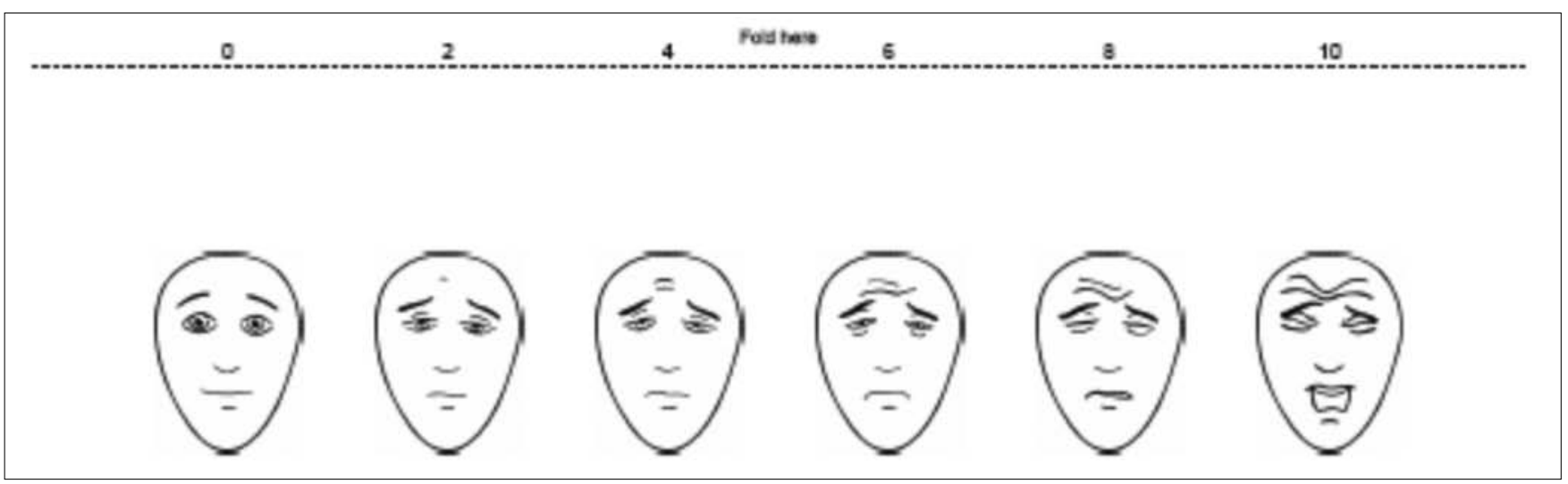




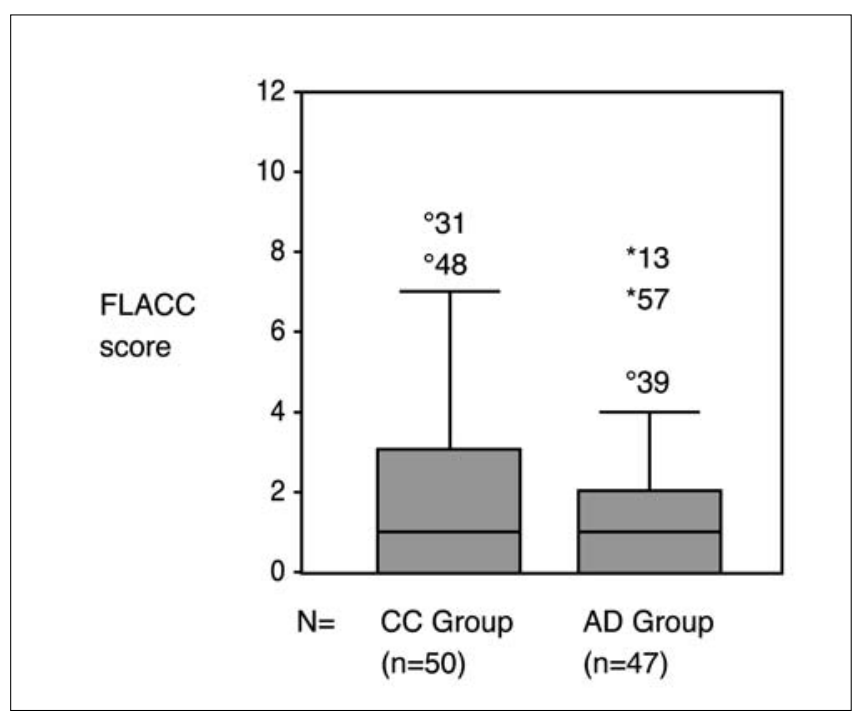

Figure 3.

Box whisker plots of the results of the FPS-R score for each group are shown. (CC group: EMLA; AD group: EMLA plus video-game). They display the median, first and third quartiles and ranges. Values over 3rd quartile +1.5 interquartile range have been considered outliers.

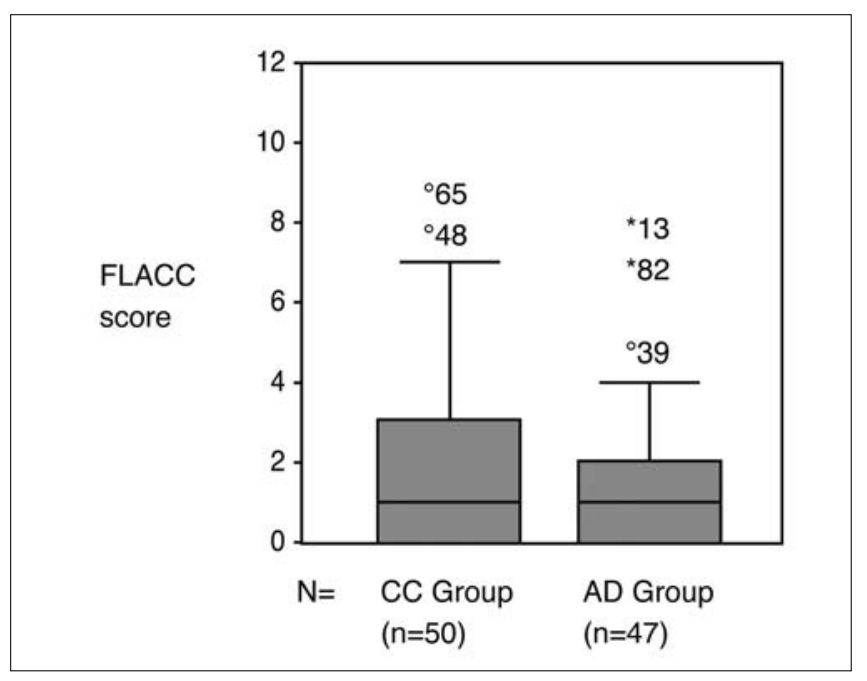

Figure 4.

Box whisker plots of the results of the FLACC score for each group are shown. (CC group: EMLA; AD group: EMLA plus video-game). They display the median, first and third quartiles and ranges. Values over 3rd quartile +1.5 interquartile range have been considered outliers.

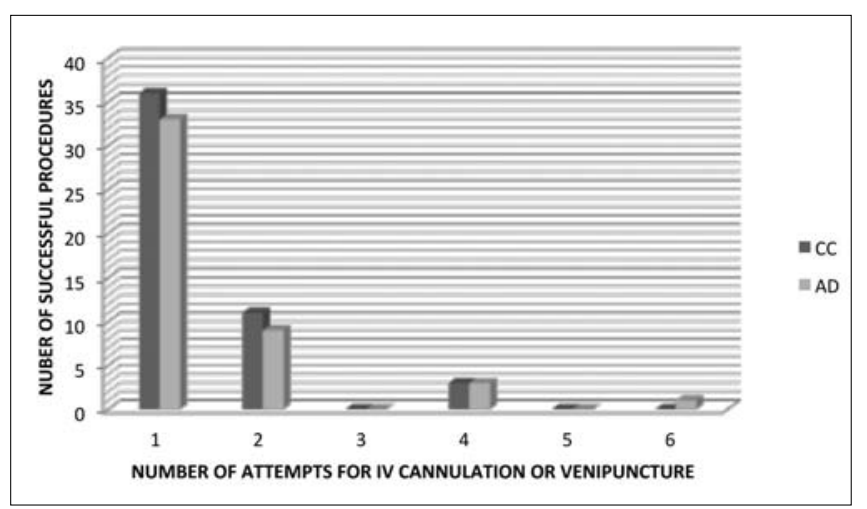

Figure 5.

Number of attempts required to perform a successful procedure
Categorical data are presented as numbers and percentages and continuous data as medians and interquartile-ranges, as data explored visually and with the Kolmogorov Smirnov test, showed a non-normal distribution. Continuous data concerning study outcomes were presented also as means and standard deviations which were more informative than medians and interquartile-ranges.

Baseline characteristics of the two groups were compared with the chi-square test for proportions and with the Mann-Whitney nonparametric test for continuous data. Differences in clinical outcomes between the two study groups were analyzed for categorical outcomes using the chi-square test; for continuous outcomes using the Mann-Whitney non-parametric test.

Two regression logistic analysis were carried out to explore the relationship between a dicothomous variable of pain (presence of clinically significant pain in FPS-R scale and in FLACC scale if score $>4$ ) and type of intervention taking into account possible unbalancing between intervention groups.

The data were analyzed using SPSS for Windows 11.0 (SPSS 2001) according to the intention-to-treat principle. All $\mathrm{p}$ values will be two-sided, with a p value of less than 0.05 used to indicate statistical significance

\section{Results}

\section{Demographic characteristics}

From April to December 2009, according to inclusion and exclusion criteria, 109 eligible children and their parents were approached about the study; 107 agreed to enter the study but only 97 were enrolled, since 4 children didn't use EMLA and 6 didn't complete the consent form in its totality.

After parents' written informed consent was obtained, 50 (51,5\%) participants were randomized to the conventional care group (CC) and $47(48,5 \%)$ were randomized to the intervention group (active distraction, AD). (see Fig 1) After randomization, in CC group 1 subject received $\mathrm{AD}$ and 1 midazolam before evaluation; in the $\mathrm{AD}$ group, 2 subjects needed physical restriction and consequently stopped playing the game. However, the analyses were carried out according to the intention-to-treat principle.

Main characteristics of the enrolled population and of the procedures are reported in table 2. The median age for both groups was 7 years. Forty-nine males and 48 females were randomized: in CC were allocated 19 (38\%) males, while in $\mathrm{AD} 30$ (64\%) males. This casual unbalance between genders was statistically significant $(\mathrm{p}=0.01)$. The number of procedures, which children had previously undergone, was extremely variable, with some children at their first experience and others who had undergone more than fifty procedures. In CC group the median was 6 (interquartile range 3-15), while in the $\mathrm{AD}$ group the median was 5 (interquartile range 2-15).

Forty-three venipunctures and 54 IV cannulations were performed. At first attempt, each procedure was performed optionally on hands or elbows (Tab. 2). The unbalance between the two procedures in $\mathrm{AD}$ group was not statistically significant. 


\begin{tabular}{llll}
\hline Tabella 1 & & & \\
& & FLACC BEHAVIORAL PAIN ASSESSMENT ${ }^{22}$ & \\
\hline Face & 0 & 1 & 2 \\
\hline Legs & No particular expession or smile & $\begin{array}{l}\text { Occasional grimace or frown, } \\
\text { withdrawn, disinterested }\end{array}$ & $\begin{array}{l}\text { Frequent to constant quivering chin, } \\
\text { clenched jaw }\end{array}$ \\
\hline Activity & Normal position or relaxed & Uneasy, restless, tense & Kicking or legs drawn up \\
\hline Cry & Lying quietly, normal position, moves easily & Squirming, shifting back and forth, tense & Arched, rigid or jerking \\
\hline Consolability & No cry (awake or asleep) & Moans or whimpers; occasional complaint & $\begin{array}{l}\text { Crying steadily, screams or sobs, } \\
\text { frequent complaints }\end{array}$ \\
\hline
\end{tabular}

Tabella 2

BASELINE AND PROCEDURE CHARACTERISTICS

\begin{tabular}{|c|c|c|}
\hline Characteristics & nal pain management $(n=50)$ & Active distraction $(n=47)$ \\
\hline Age (years), median (interquartile range) & $7(6-8)$ & $7(5-8)$ \\
\hline Male sex (\%) & $19(38 \%)$ & $30(64 \%)^{\star \star}$ \\
\hline Number of children's previous procedures, median (interquartile range) & $6(3.5-15)$ & $5(2-15)$ \\
\hline $\begin{array}{l}\text { Procedure: number }(\%) \\
\text { venipuncture }(\%) \\
\text { IV cannulation }(\%)\end{array}$ & $\begin{array}{l}26(52 \%) \\
24(48 \%)\end{array}$ & $\begin{array}{l}17(36 \%) \\
30(64 \%)\end{array}$ \\
\hline $\begin{array}{l}\text { Site of first attempt: number }(\%) \\
\text { hand }(\%) \\
\text { elbow }(\%)\end{array}$ & $\begin{array}{l}23(46 \%) \\
27(54 \%)\end{array}$ & $\begin{array}{l}27(57 \%) \\
20(43 \%)\end{array}$ \\
\hline $\begin{array}{l}\text { Site of successful procedure: number }(\%) \\
\text { Hand }(\%) \\
\text { Elbow }(\%) \\
\text { Foot }(\%)\end{array}$ & $\begin{array}{l}25(50 \%) \\
25(50 \%)\end{array}$ & $\begin{aligned} 26 & (55 \%) \\
20 & (43 \%) \\
1 & (2 \%)\end{aligned}$ \\
\hline EMLA application: number (\%) & $49(98 \%)$ & $45(96 \%)$ \\
\hline Time of maintained EMLA on the site of the first two procedures, minutes, median (interquartile rang & $90(60-105)$ & $90(60-120)$ \\
\hline
\end{tabular}

All randomized subjects maintained EMLA on the site of the first two procedures for more than 60 minutes, but three of those subjects who needed more than two attempts ( 1 in CC group and 2 in $\mathrm{AD}$ group) didn't have EMLA on the site of the successful procedure. (Tab. 2)

\section{Outcomes:}

No differences in self-report level of pain evaluated with FPS-R scale were found: results showed in both groups a median score of 0 (interquartile range: $0-2$, and a mean score of 1.36 (SD 2.5) in CC group vs 1.5 (SD 2.5) in AD group. Significant pain (FPS-R>4) occurred in 4 (8\%) subjects in CC group and in $4(9 \%)$ subjects in $\mathrm{AD}$ group. (Fig 3)

According to the observer's evaluation, rated with FLACC Behavioral Pain Assessment, no statistically significant differences were found: the median score was 1 in both groups (interquartile range $0-3$ in $\mathrm{CC}$ group; $0-2$ in $\mathrm{AD}$ group) and the mean score was 2.1 (SD 2.7) in CC group vs 1.5 (SD 2.3) in AD group. Significant pain (FLACC>4) occurred in $9(18 \%)$ children in CC group and in $4(9 \%)$ children in $\mathrm{AD}$ group. This difference wasn't statistically significant ( $\mathrm{p}=0.2$ ). (Fig 4)

Considering the attempts that were necessary to perform a successful procedure, data showed that $36(72 \%)$ procedures in CC group and $33(72 \%)$ procedures in $\mathrm{AD}$ group were successful at first attempt. The median of necessary attempts is 1 in both groups (interquartile range: 1-2). (Fig 5)

In order to evaluate if the unbalances between the two groups for sex and type of procedure could have influenced the main outcomes of the study (FPS-R and FLACC scales), univariate analysis was carried out to evaluate differences in pain between male vs female and between venipuncture and cannulation. These analysis didn't show any statistically significant difference.

No child refused to play and more than $70 \%$ asked to play further well after the end of the procedures. Nurses appreciated this technique too and the caregivers of the Day Hospital Unit asked for hardware and software to go on with the active distraction even after the conclusion of study period.

\section{Discussion}

Pain consists of two different elements, nociception and suffering. The latter is linked with emotional and cognitive aspects. Therefore adding a distraction technique to standard care of procedural pain may rationally improve pain control. This endpoint is important for routine procedures such as venipuncture and IV cannulation, particularly for chronically ill children, since it is very likely that they will experience such procedures repeatedly in their lifetime. It is well known that previous experience can shape future pain perception and that patients don't get used to pain ${ }^{27}$.

In the literature there are many studies that evaluated the efficacy of distraction in reducing procedural pain, as shown in Kleiber and Harper's metanalysis ${ }^{10}$. However, we could not find exhaustive studies that investigated venous accesses, EMLA premedication and active distraction at the same time. Only the study by WindichBiermeier et al. approached these three items, using both active (soap bubbles, Game Boy ${ }^{\circ}$, interactive books) and passive (audio- 
books, Virtual Reality Glasses) distracters. These authors stated that distraction itself is efficient in reducing pain, but they weren't able to rate single distracters' efficacy 28.

Our data show that there is no difference in self-reported pain when adding a videogame distraction technique to EMLA cream. This could be because of the high efficacy of topical anesthesia in this setting. Considering that "severe pain" is defined for FPS rates $>4$, it is evident that standard analgesia's efficacy is equal to $90 \%$ in the control group, making very difficult to increase its efficacy by adding active distraction. We might suppose that this depended on EMLA's efficacy but this conclusion should have been validated by adding a third group of randomization, in which children who played with the videogame wouldn't have been premedicated with EMLA cream.

According to FLACC scale, the observer's evaluation based on behavioral parameters that are influenced not only by biochemical but also by emotional factors, there isn't evidence of a difference between the two groups as well. None-the-less it is interesting to notice that in the control group there are twice as many subjects with significant distress (FLACC $>4$ ) as in the intervention group: $18 \%$ versus $9 \%$. Even if this difference isn't statistically significant ( $p=0.2$ ), it shows a decreasing trend that is possibly connected with the affective-cognitive aspect of pain. This issue could be addressed in a wider population and in the setting of a more painful procedure.

We need to underline the fact that the pain scores we obtained were very low, lower than other studies and therefore lower than expected, especially given the youth of the patients involved. This result may depend on the expertise of the folks doing the procedures and it should be further evaluated.

A further analyzed outcome was the number of attempts necessary to perform a successful procedure: also according to this parameter there was not a statistically significant difference. In both groups $70 \%$ procedures were successfully performed at first attempt and $90 \%$ at second. These data shows that an active distraction with videogames is applicable during venipuncture or IV cannulation, since it doesn't interfere with the procedures, not increasing the number of attempts. This result may be relevant for studies in different settings, such as other painful procedures (e.g. suturing in the emergency room).

This study presents some limitations. First, it wasn't possible to blind the evaluators. Since the intervention was whether children play with the videogame or not, the patients and their parents were aware of the group they belong to and so were the operators. We previously assessed the literature to find out whether there was a pain assessment scale based only on facial observation in order to convey blindness to the study by adding a second observer, who could have given an opinion on a close-up video recording of the patient, but, to the best of our knowledge, we weren't able to find any scale which fitted the age group we investigated.

Second, randomization generated a casual unbalance between groups that was showed for sex and type of procedure. However, multivariate analysis didn't show any effect of these variables on study outcomes. Third, this study was designed as superiority trial and the sample size was calculated on the hypothesis that EMLA plus active distraction offered an advantage over EMLA alone, as reported by previous literature. We didn't confirm this figure, for the reasons described above. Therefore, this study is underpowered to exclude the existence of some differences between the 2 groups. However, given the observed results, it's unlikely that we missed clinical relevant differences for the study main outcome.

We can conclude that in this experience active distraction did not improve EMLA analgesia for IV cannulation and venipuncture. None the less, active distraction was easily applicable and appreciated by children and staff. This technique could be usefully investigated in other painful procedures; its efficacy may be better evaluated by adding distress or anxiety scores.

\section{References}

1 Mc Murtry CM. Needle and dread: Is it just a little poke? A call for implementation of evidence-based policies for the management of needle pain in clinical settings. Paediatr Child Health. 2007; 12 (2) : 101-102

2 Cummings EA, Reid GJ, Finley GA, McGrath PJ, Ritchie JA. Prevalence and source of pain in pediatrics inpatients. Pain. 1996; 69: 25-31

3 Fradet C, Mc Grath PJ, Kay J, Adams S, Luke B. A prospective survey of reaction to blood tests by children and adolescents. Pain. 1990,40:53-60

4 Kennedy RM, Luhmann J, Zempsky WT. Clinical implications on unmanaged needle-insertion pain and distress in children. Pediatrics. 2008; 122: S130-S133

5 Pate JT, Blount RL, Cohen LL, Smith AJ. Childhood medical experience and temperament as predictors of adult functioning in medical situations. Child Health Care. 1996; 25 (4): 39-46

6 Tak JH, van Bon WH. Pain- and distress- reducing interventions for venipuncture in children. Child Care Health Dev. 2006; 32(3): 257-268

Suls J, Wan CK. Effects of sensorial and procedural information on coping with stressful medical procedures and pain: a meta-analysis. J Consult Clin Psychol. 1989; 57(3): 372-379

8 Cohen LL. Behavioral approaches to anxiety and pain management for pediatric venous access. Pediatrics. 2008; 122: S134-S139

9 Cavender K, Goff MD, Hollon EC, Guzzetta CE. Parents' positioning and distracting children during venipuncture: effects on children's pain, fear and distress. J Holist Nurs. 2004; 22(1): 32-56

10 Kleiber C, Harper DC. Effects of distraction on children's pain and distress during medical procedures: a meta-analysis. Nursing Research. 1999; 48(1): 44-49

11 Fernandez E. A classification system of cognitive coping strategies for pain. Pain. 1986; 26(2): 141-151

12 Mc Caul KD, Malott JM. Distraction and coping with pain. Psychol Bull. 1984; 95(3):516-33

13 Mc Grath P. Intervention and management. In: Bush JP, Arkins SW, eds. Children in pain: Clinical and research issues from a developmental perspective. New York, NY: Springer; 1991: 83-115

14 Melzack R, Wall PD. Pain mechanisms: a new theory. Science. 1965; 150(699): 971-979 
15 Mason S, Johnsons MH, Woolley C. A comparison of distracters for controlling distress in young children during medical procedures. Journal of Clinical Psychology in Medical Settings. 1999; 3(6): 239-248

16 Blount R, Piira T. Management of pediatric pain and distress due to medical procedures. In: Roberts MC, ed. Handbook of Pediatric Psychology. 3rd ed. New York, NY. Guilford Press; 2003: 216-233

17 De More M, Cohen LL. Distraction for pediatric immunization pain: a critical review. J Clin Psychol Med Settings. 2005; 12(4):281-291

18 Hallen B, Uppfeldt A. Does lidocaine-prilocaine cream permit painfree insertion of IV catheters in children? Anesthesiology. 1982; 57: 340-342

19 Fetzer SJ. Reducing venipuncture and intravenous inserction pain with eutectic mixture of local anesthetic. A meta-analysis. Nursing Research. 2002; 51(2): 119-124

20 Bieri D, Reeve R, Champion GD, Addicoat L, Ziegler JB. The Faces Pain Scale for self-assesment of the severity of pain experienced by children: Development, initial validation and preliminary investigation for ratio scale properties. Pain. 1990; 41: 139-150

21 Hicks CL, Von Baeyer CL, Spafford PA, van Korlaar I, Goodenough B. The Faces Pain Scale-Revised: toward a common metric in pediatric pain measurement. Pain. 2001; 93: 173-183
22 Nilsson S, Finnstrom B, Kokinsky E. The FLACC behavioral scale for procedural pain assessment in children aged 5-16 years. Pediatr Anesth. 2008; 18(8): 767-774

23 Merkel SI, Voepel-Lewis T, Shayevitz JR, Malviya S. The FLACC: a behavioral scale for scoring postoperative pain in young children. Pediatr Nurs. 1997; 23(3):293-297

24 Curtis SJ, Jou H, Ali S, Vandermeer B, Klassen T. A randomized controlled trial of sucrose and/or pacifier as analgesia for infants receiving venipuncture in a pediatric emergency department. BMC Pediatr. 2007 Jul 18;7:27.

25 Gold JI, Kim SH, Kant AJ, Joseph MH, Rizzo AS. Effectiveness of virtual reality for pediatric pain distraction during i. v. placement. Cyberpsychol. Behav. 2006; 9 (2): 207-12

26 Taddio A, Soin HK, Schuh S, Koren G, Scolnik D. Liposomal lidocaine to improve procedural success rates and reduce procedural pain among children: a randomized controlled trial. CMAJ 2005;172(13):1691-5.

27 Porter FL, Grunau RE, Anand KJ. Long-term effects of pain in infants. J Dev Pain Behav Pediatr. 1999;20(4):253-261

28 ùWindich-Biermeier A, Sjoberg I, Dale JC, Eshelman D, Guzzetta CE.. Effects of distraction on pain, fear, and distress during venous port access and venipuncture in children and adolescents with cancer. J Pediatr Oncol Nurs. 2007 Jan-Feb;24(1):8-19 